\title{
Estimation of crop growth from optical and microwave soil cover
}

\author{
B. A. M. BOUMAN \\ Centre for Agrobiological Research, Bornsesteeg 65, \\ P.O. Box 14, 6700 AA Wageningen, The Netherlands \\ and J. GOUDRIAAN \\ Department of Theoretical Production Ecology, Agricultural University, \\ P.O. Box 430, 6700 AA Wageningen, The Netherlands
}

(Received 2 May 1988; in final form 16 November 1988)

\begin{abstract}
Direct derivation of biomass from radar backscattering gives erratic results so this paper discusses another method in which biomass was not estimated directly but was found as the accumulated value of the estimated crop growth rate. The estimation was based on soil crop cover and global radiation. The relationship between soil cover in the optical and microwave regions was investigated. Analysis of the methodology showed that improvement is obtained in comparison with the direct estimation method. Despite variation in parameters for different years, a remarkable consistency in estimated biomass was observed. Nevertheless, measurements of radar backscattering still suffer from too much variation to be reliable for biomass estimation.
\end{abstract}

\section{Introduction}

In contrast to remote sensing in the optical region, radar remote sensing is hindered very little by clouds, fog or absence of global radiation during the night. Therefore, radar remote sensing provides a more reliable frequency for data collection and can be useful for a variety of land applications. In agriculture, a general demand exists for up-to-date inventories, and classifications of forests and field crops. Such inventories, however, only fulfil primary needs. Further interests are vested upon themes such as the monitoring of crop growth and development and ultimately yield forecasting (ESA Land Applications Working Group 1987). Up to now, much research work has been done in the field of classification with promising results (Hoogeboom 1983, 1986, Binnenkade 1986), but research in the field of growth monitoring and yield prediction has made little progress. The great practical advantages of radar remote sensing are offset by the difficulties that have existed so far in the interpretation of the backscattering data and in their conversion into biomass or into other meaningful crop characteristics. In 1987 the MONISAR project (MONItoring with Synthetic Aperture Radar) was initiated in the Netherlands to investigate the possibilities for estimating crop growth and development from radar backscattering. For this purpose radar remote sensing data were integrated into crop growth models. These models are based on relationships between the physiological processes of plants and environmental factors such as solar radiation, temperature, day length, water and nutrient availability, etc. The development of these models for sub-optimal growing conditions is difficult and estimates of crop growth often turn out to be inaccurate. If remote sensing techniques can be used to yield information about the actual status of a crop, growth models can be adjusted and more accurate predictions of crop growth can be made. 
In this paper an attempt is made to develop a method for integrating radar remote sensing data and a basic crop growth model. The data used for this study have been derived from ground-based radar experiments conducted by the ROVE (Radar Observation of VEgetation) team in the Netherlands in 1979 and 1980 (de Loor et al. 1976). The radar system utilized was an X-band scatterometer, operating at $9 \cdot 5 \mathrm{GHz}$ frequency. Measurements made at vertical like-polarizations (VV) on the crops beet, pea and potato have been selected. These crops are important in European agriculture and have been studied little in radar remote sensing literature.

\section{Outline of the methodology}

\subsection{The cloud equations}

Radar remote sensing data can be converted into fresh weight by inversion of the so-called cloud equations. In these equations (Attema and Ulaby 1978, Hoekman 1981) the microwave backscattering is the weighted addition of the backscattering component of the bare soil and that of the vegetation cover. The weighting coefficient is a function of the amount of plant water (water contained in plants), $W$, in the vegetation canopy and can be called the microwave soil cover

$$
f^{\prime}=1-[\exp (-D W / \sin \theta)]
$$

The amount of plant water $W$ is the fresh weight minus the dry weight of all of the above-ground material of the crop canopy per unit soil surface. With the weighting coefficient, the microwave backscattering can be written as

$$
\gamma=C f^{\prime}+\left(1-f^{\prime}\right) G \exp (K m)
$$

where $\gamma=$ normalized radar cross-section $\left(\mathrm{m}^{2} / \mathrm{m}^{2}\right), \theta=$ grazing angle, $C=$ backscattering coefficient of an optically thick vegetation cover and is angle dependent $\left(\mathrm{m}^{2} \mathrm{~m}^{2}\right)$, $G=$ backscattering of dry soil (also angle dependent) $\left(\mathrm{m}^{2} / \mathrm{m}^{2}\right), W=$ plant water $\left(\mathrm{kg} / \mathrm{m}^{2}\right), m=$ volumetric moisture content of the top soil (per cent), $K=$ moisture coefficient of soil per volumetric moisture content and $D=$ coefficient of attenuation per unit of plant water.

This relation is based on the exponential extinction of microwave radiation by the amount of plant water in the vegetation canopy. The parameter $D$ is the coefficient of attentuation and gives the extinction of microwaves of a unit of plant water in the canopy. The parameter $G$ is soil-specific and must be determined by regression on microwave backscattering data for bare soil. The parameter $K$ is less soil-specific and its value is about 0.051 (Hoekman et al. 1982). The parameters $D$ and $C$ are cropspecific and must be determined by regression on microwave backscattering data for crop-soil systems, using previously determined $G$ and $K$ values for the soil underneath the crop. If a series of measurements from bare soil exists throughout a growing season until the harvest, all four parameters can be determined in the same regression. Since the parameters $C$ and $G$ are dependent on the grazing angle of the radar, the regressions must be made for each grazing angle separately. The cloud equations comprise a set of the same equations with parameters for different grazing angles. An example of parameters collected in this way is given in table 1. If these parameters are known, inversion of the measured backscattering values is, in principle, possible in order to find $W$ and $m$, by using data for different grazing angles $\theta$. If the relative water content of the crop canopy is known from previous measurements, the amount of plant water can be used to calculate a direct estimate of dry canopy biomass. 
Table 1. Cloud parameters for some crops and soils, X-band radar (9.5 GHz), vertical likepolarization. From Hoekman (1979) and Kasteren (personal communication, 1988). The soils are alluvial clay at 'Test Farm De Bouwing', 1979, and marine clay at 'Test Farm De Schreef,' 1980.

\begin{tabular}{|c|c|c|c|c|c|c|c|c|}
\hline \multirow[b]{2}{*}{ Grazing angle } & \multicolumn{3}{|c|}{$C$} & \multicolumn{3}{|c|}{$G$} & \multirow[t]{2}{*}{$D$} & \multirow[t]{2}{*}{$K$} \\
\hline & $20^{\circ}$ & $40^{\circ}$ & $80^{\circ}$ & $20^{\circ}$ & $40^{\circ}$ & $80^{\circ}$ & & \\
\hline Beet 1979 & $0 \cdot 72$ & $0 \cdot 87$ & 0.92 & $0 \cdot 02$ & 0.04 & 0.48 & $0 \cdot 76$ & 0.05 \\
\hline Beet 1980 & $0 \cdot 98$ & $1 \cdot 17$ & 1.06 & $0 \cdot 06$ & 0.08 & 0.53 & $0 \cdot 46$ & 0.05 \\
\hline Peas 1979 & $0 \cdot 39$ & $0 \cdot 41$ & $0 \cdot 22$ & 0.03 & 0.06 & 0.43 & 0.41 & 0.05 \\
\hline Peas 1980 & $0 \cdot 41$ & $0 \cdot 49$ & 0.53 & $0 \cdot 03$ & 0.06 & $0 \cdot 38$ & 0.94 & 0.05 \\
\hline Potatoes 1979 & $0 \cdot 37$ & 0.73 & 1.73 & $0 \cdot 03$ & 0.07 & $0 \cdot 18$ & $0 \cdot 25$ & 0.05 \\
\hline Potatoes 1980 & $0 \cdot 32$ & 0.49 & $0 \cdot 87$ & 0.09 & $0 \cdot 14$ & $0 \cdot 21$ & $1 \cdot 02$ & 0.05 \\
\hline
\end{tabular}

In practice, this inversion turns out to be loaded with difficulties, especially when there is a lack of contrast between crop and soil, as occurs with potatoes (Bouman 1988). Secondly, in many crops, especially cereals, the parameters $D$ and $C$ have a strong azimuthal component governed by the orientation of the scatter elements, i.e. stems, leaves and ears (Kasteren, 1981, Ulaby and Allen 1984). This orientation is influenced by meteorological conditions and thereby introduces a dependency of the radar backscattering on the weather during measurements. Thirdly, the cloud parameters for the same crop may vary in different years (table 1).

Beet causes fewer problems and attention was focused on this crop for further analysis. Potatoes and peas have been used for comparison. The results of a direct inversion of backscattering data into dry canopy biomass, through the estimated amount of plant water and a measured value for the relative plant water content, are given for beet in two growing seasons (figure 1).

The results have been obtained by using the cloud parameters collected for the same crop and the same year. To simulate future practical conditions only two angles were used for the inversion, $40^{\circ}$ and $80^{\circ}$ grazing angles. Because there are two parameters to be estimated, plant water and soil moisture, a minimum of two independent backscattering measurements are needed. The high grazing angles were chosen because the radar backscattering responds for a greater length of time to crop growth at high grazing angles than at low grazing angles. At a grazing angle of $20^{\circ}$ the radar backscattering of beet reaches a saturation level relatively early in the growing season (Bouman 1987). In 1979 the calculated biomass followed the observed biomass with fluctuations until the end of July (figure $1(a)$ ). In 1980 only six measurements out of thirty could be inverted to derive biomass values (figure 1 $(b)$ ). Due to the fluctuating pattern of the backscattering measurements, twenty-four measurements fell outside the model range of grazing angles of $40^{\circ}$ and $80^{\circ}$ set by the factors $G \exp (\mathrm{Km})$ and $C$. When backscattering measurements at more than two grazing angles are used for the inversion, the parameters plant water and soil moisture are over-determined. Optimization techniques can then be used to arrive at a larger number of estimations of plant water with a better accuracy. However, a large number of grazing angles imposes practical problems for radar remote sensing from airborne or spaceborne platforms. 


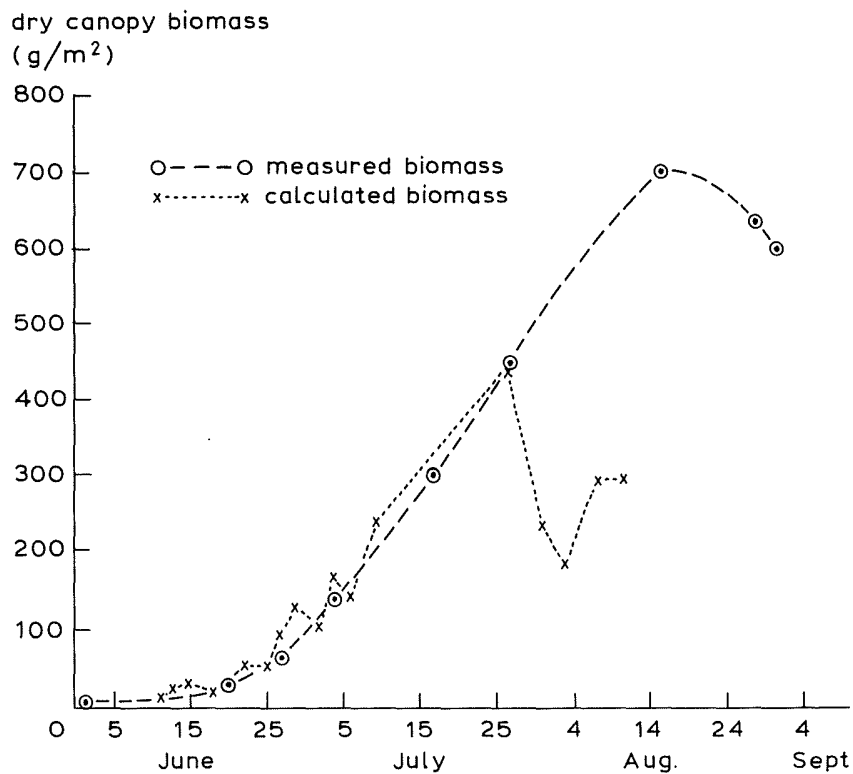

(a)

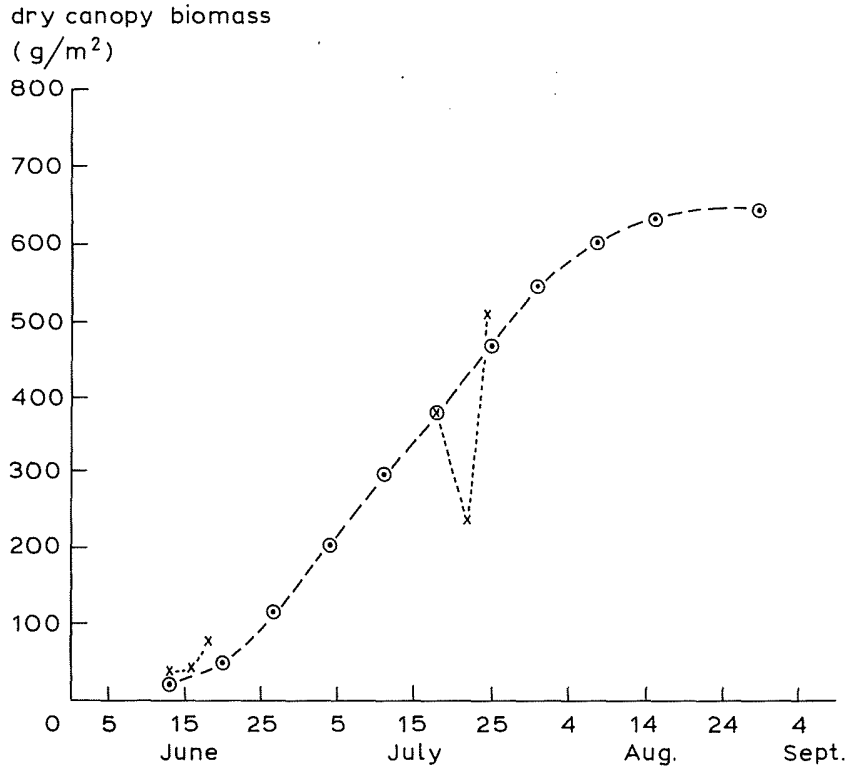

(b)

Figure 1. Measured and calculated dry canopy biomass as a function of time for beet $(a)$ in 1979 and $(b)$ in 1980. The calculated biomass is derived from the relative plant water content of a beet canopy, an average of 90 per cent, and from the amount of plant water estimated from the inversion of the cloud equations. 


\subsection{Crop growth rate and intercepted radiation}

The poor quality of the results of this direct method necessitates another way of using the data, based on the presumption that the real crop does not fluctuate in biomass as figure 1 suggests. Assuming continuity in biomass, the problem can be considered one of estimating the crop's growth rate. As shown by several authors such as Gallagher and Biscoe (1978), Milthorpe and Moorby (1979) and Monteith (1981), a crop's growth rate is closely correlated with intercepted global radiation, which can be estimated as the product of global radiation and soil cover. This means that the dry weight, $W_{\mathrm{d}}$, of the crop is written as

with

$$
W_{\mathrm{d}}=\int R d t
$$

$$
R=\alpha S f
$$

where $R=$ growth rate of the crop (g/day), $\alpha=$ conversion efficiency to dry weight $(\mathrm{g} / \mathrm{J}), S=$ incoming daily global radiation $\left(\mathrm{J} / \mathrm{m}^{2} /\right.$ day $), f=$ fraction of green soil cover and $W_{\mathrm{d}}=$ dry weight of the crop $(\mathrm{g})$.

Our approach here was to estimate the soil crop cover from radar data and then multiply it by the global radiation collected in the conventional way. The following outlines the development of the method.

The first step was to derive the conversion efficiency $\alpha$ between crop growth rate, $R$, and intercepted global radiation, $S f$, based on collected ground truth data (see figure 2).

$$
\left.\begin{array}{l}
W_{\mathrm{d}} \text { (measured) } \\
\int S f \text { (measured) }
\end{array}\right\} W_{\mathrm{d}}=\alpha \int(S f) d t \rightarrow \alpha
$$

Next, the regression coefficient $\beta$ between the optical soil cover $f$, estimated in the field, and the microwave soil cover $f^{\prime}$, computed from the measured amount of plant water $W$, was calculated (figure 3 ).

$$
\left.\begin{array}{l}
f \text { (estimated) } \\
\left.f^{\prime} \text { (calculated from measured } W\right)
\end{array}\right\} f=\beta f^{\prime} \rightarrow \beta
$$

Then, as in equations (3) and (4), the optical soil cover was replaced by the regression coefficient $\beta$, multiplied by the calculated microwave soil cover (figure 4).

$$
W_{\mathrm{d}}=\alpha \beta \int\left(S f^{\prime}\right) d t
$$

where $f^{\prime}$ is calculated from measured $W$.

Finally, the microwave soil cover calculated from the measured value for $W$ was replaced by the microwave soil cover derived from radar backscattering measurements (figure 5).

$$
W_{\mathrm{d}}=\alpha \beta \int\left(S f^{\prime}\right) d t
$$

where $f^{\prime}$ is calculated from backscattering measurements.

\section{Calculation of the parameters $\alpha$ and $\beta$}

\subsection{Conversion efficiency $\alpha$}

Based on the ground truth collected in 1979 at 'Test Farm De Bouwing' and in 1980 at 'Test Farm De Schreef', the values for the efficiency factor $\alpha$ were derived (table 2). The test farms are located in ecologically different areas some $50 \mathrm{~km}$ apart. 
Table 2. Conversion efficiency $\alpha$ of intercepted global radiation to dry weight of the crop canopy $(\mu \mathrm{g} / \mathbf{J})$.

\begin{tabular}{lccc}
\hline & 1979 & 1980 & 1979 and 1980 \\
\hline Beet & 1.12 & 1.74 & 1.35 \\
Peas & 1.29 & 1.89 & 1.65 \\
Potatoes & 1.03 & 1.02 & 1.03 \\
\hline
\end{tabular}

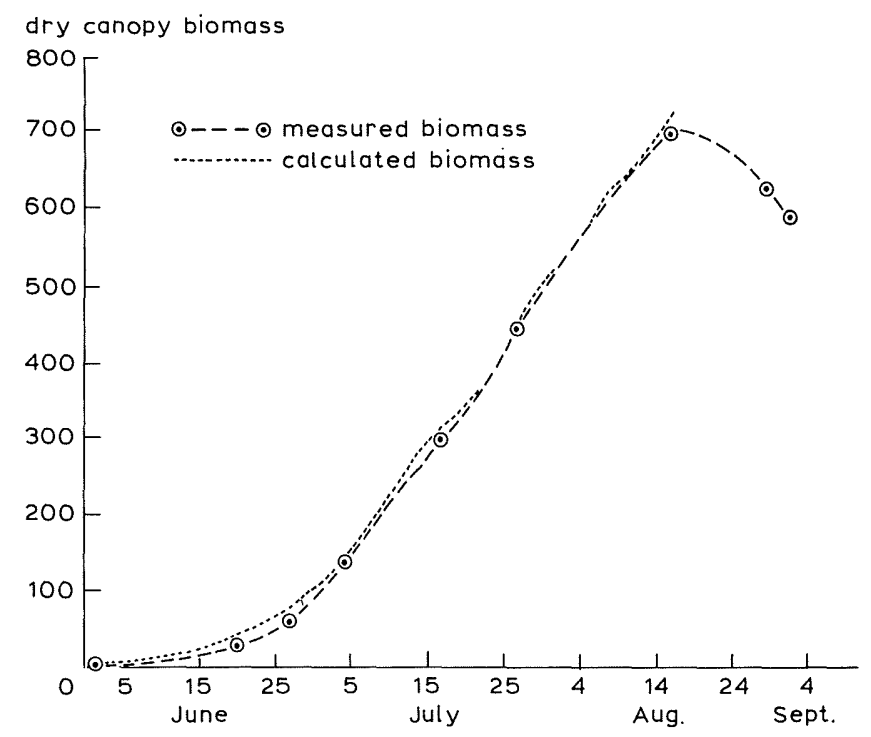

Figure 2. Measured and calculated dry canopy biomass of beet, 1979. The calculated biomass was found by accumulation of intercepted global radiation multiplied by the conversion efficiency derived from regression on the same data.

These data were derived from visually estimated crop cover and measured values of the canopy biomass. Due to the nature of the study, no ground truth was collected with regard to tuber biomass. Therefore, only data for the first two months of the growing season were taken into consideration in order to minimize the disturbance caused by preferential growth of subsurface tubers. As a check for the method above, the integrated value of the crop growth rate of beet was calculated in this way and the measured canopy dry weight were plotted together (figure 2). The regression parameter, $\alpha$, was not obtained independently of the data. Therefore, only the variability around the measured line can be used as an indication of the efficiency of this step of the method.

\subsection{Optical and microwave soil cover}

Given the good quality of the results given in figure 2, which were based exclusively on ground truth data, the next step was to extend the method to using 
Table 3. Regression coefficient, $\beta$, between optical soil cover, $f$, and calculated microwave soil cover, $f^{\prime}$, at $80^{\circ}$ grazing angle, $f=\beta \mathrm{f}^{\prime}$.

\begin{tabular}{ccc}
\hline Beet & Peas & Potatoes \\
\hline 1.07 & 1.69 & 2.54 \\
\hline
\end{tabular}

radar data for estimating the soil cover. To eliminate the disturbance from soil backscattering and meteorological influences on the crop canopy, microwave soil cover values were generated that were expected theoretically on the basis of equation (1). The input values for this equation were the ground truth data for the amount of plant water, $W$, and the values for $D$ which gave the best correlations between the backscattering calculated by means of the cloud model and the measured backscattering (Bouman 1987). The results are plotted against the visually estimated soil cover data for beet, peas and potatoes (figure 3). In figure 3, the data for 1979 and 1980 are combined for beet and potatoes. In figure $3(a)$, the relationship between optical and microwave soil cover for beet is an S-shaped curve, although large linear stretches exist at all grazing angles. In figure $3(b)$, near-linear relationships are observed for potatoes. For peas (figure $3(c)$ ), linear relationships only exist for the period of vegetative growth which agrees with the limited applicability of the cloud equations (Bouman 1987). Because $f^{\prime}$ and $f$ were almost linearly related over fairly large ranges, linear regression was used. The regression coefficients were calculated between the visually estimated soil cover and the theoretically expected microwave soil cover at an $80^{\circ}$ grazing angle (table 3 ).

The differences between the results for the crop species were due to the differences in transparency of the crop canopies to microwaves relative to the transparency in the optical region. A large value for the coefficient of attenuation, $D$, for beet coincided with a low coefficient of regression, while a low value of $D$ for potatoes coincided with a high value of the coefficient. The different values of $D$ for beet in 1979 and 1980 coincided with similar differences in the optical transparency. Therefore, the relationship between optical and microwave soil cover of the crop was the same in both years (figure 3).

\section{From microwave soil cover to canopy biomass}

The two steps discussed above had to be combined and checked in their combined functioning. The dry weight of the crop canopy, $W_{\mathrm{d}}$ (in g), was written as

$$
W_{\mathrm{d}}=\alpha \beta \int\left(S f^{\prime}\right) d t
$$

Using the conversion efficiency and the coefficient of regression calculated above and the microwave soil cover calculated from the measured amount of plant water, the integrated value of the crop growth rate was computed. Compared with figure 2, this step in the method did not lead to an increase in the deviation of the calculated biomass from the measured biomass.

The last step was to derive the microwave soil cover from the radar observations instead of from the ground truth measurements as is described above. From inversion of the cloud equations, the amount of plant water was estimated from backscattering measurements. This estimation was used to calculate the microwave soil cover with the aid of equation (1). Using the microwave soil cover thus obtained, the integrated 


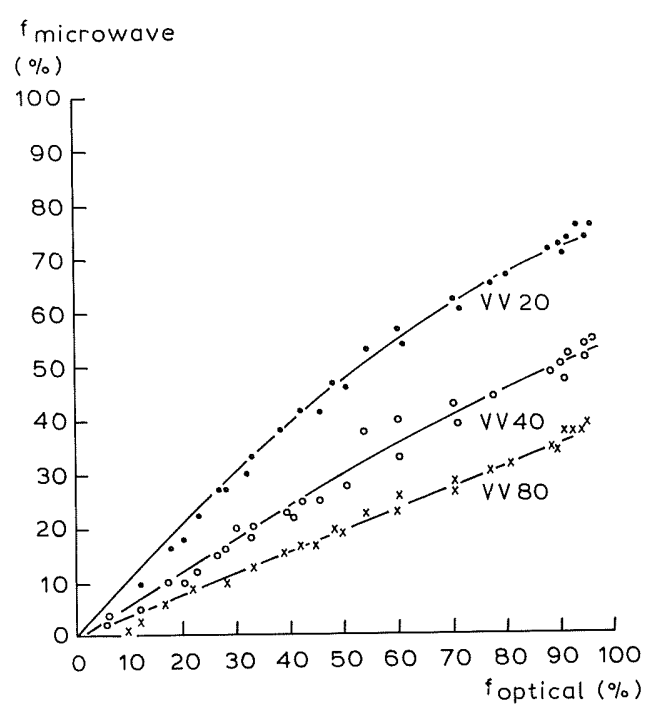

(a)

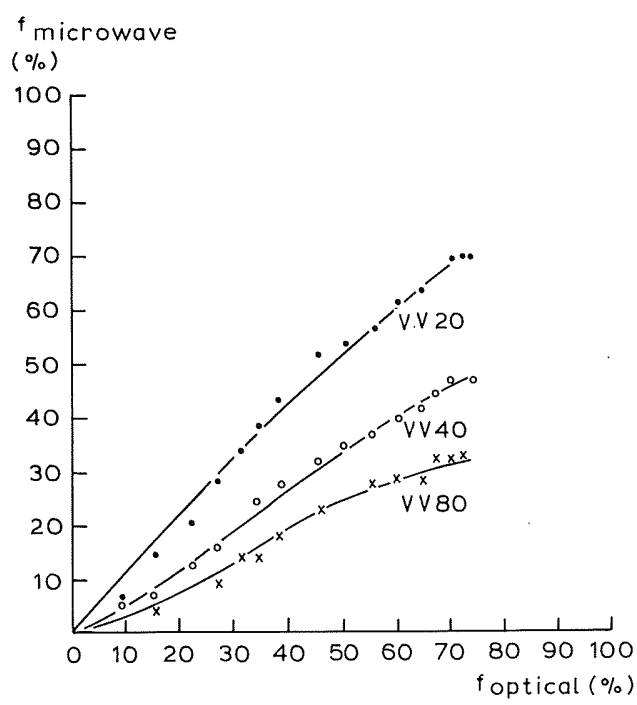

(b)

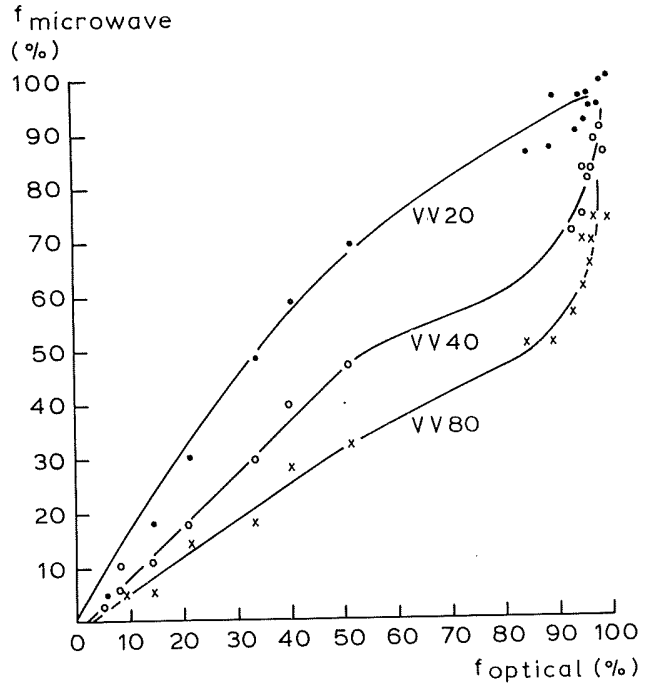

(c)

Figure 3. Visually estimated soil cover, $f$, versus theoretically expected microwave soil cover $f^{\prime}$, calculated from equation (1) from ground truth data and $D$ values found by regression: beet (1979) $D=0 \cdot 76$, beet $(1980) D=0 \cdot 46$, potatoes $(1979,1980) D=0 \cdot 25$, peas $(1979,1980) D=0.41$. Graphs are given $(a)$ for beet, $(b)$ for potatoes and $(c)$ for peas, for different grazing angles: VV20, VV40 and VV80: vertical like-polarized radar waves at respectively $20^{\circ}, 40^{\circ}$ and $80^{\circ}$ grazing angles. 


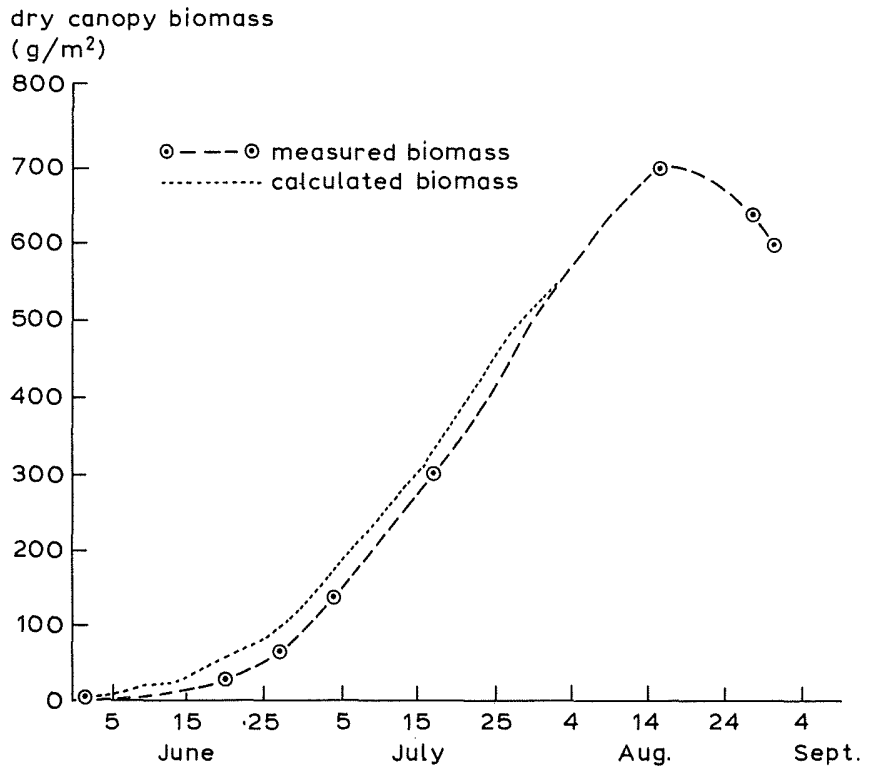

Figure 4. Measured and calculated dry canopy biomass of beet, 1979. See text for method of calculating dry biomass.

value of the crop growth rate could again be calculated with equations (3) and (4). In figure 4 , this value was plotted in time together with the measured dry biomass of the crop canopy. It should be remembered that the coefficient of regression, $\beta$, the conversion efficiency, $\alpha$, and the cloud parameters were derived from the same set of data. The results were only used for the comparison of this method with results from the direct estimation of canopy biomass (figure 1).

Compared with figure 1, the method we developed led to an improvement in the calculation of the canopy biomass. The fluctuations in the curve of the calculated biomass in time had disappeared and a more realistic estimation of the biomass was obtained at the level of saturation of the backscattering. The calculated biomass, however, generally overestimated the measured biomass by some $25 \mathrm{~g} / \mathrm{m}^{2}$.

The method was used to predict the canopy biomass of beet from radar measurements during field experiments in 1981. That year, 15 radar measurements were made during the first two months of the growing season at the same location as in 1980. In figure 5, the estimated canopy biomass is plotted together with the measured biomass. It shows the directly estimated biomass, calculated from the estimated amount of plant water by inversion of the cloud equations of 1980 and the relative water content of a beet canopy ( 90 per cent), and the continuously estimated biomass, based on the estimated microwave soil cover and the amount of global radiation measured in the field. In figure $5(a)$ the calculation of the estimated biomass is based on the cloud parameters and conversion efficiency derived from the experiment in 1980. In figure $5(b)$ the calculation is based on the cloud parameters and the conversion efficiency from the experiment in 1979.

When the cloud parameters in 1980 were used, 12 out of the 15 radar measurements could be inverted to yield estimates of the amount of plant water. By using the 


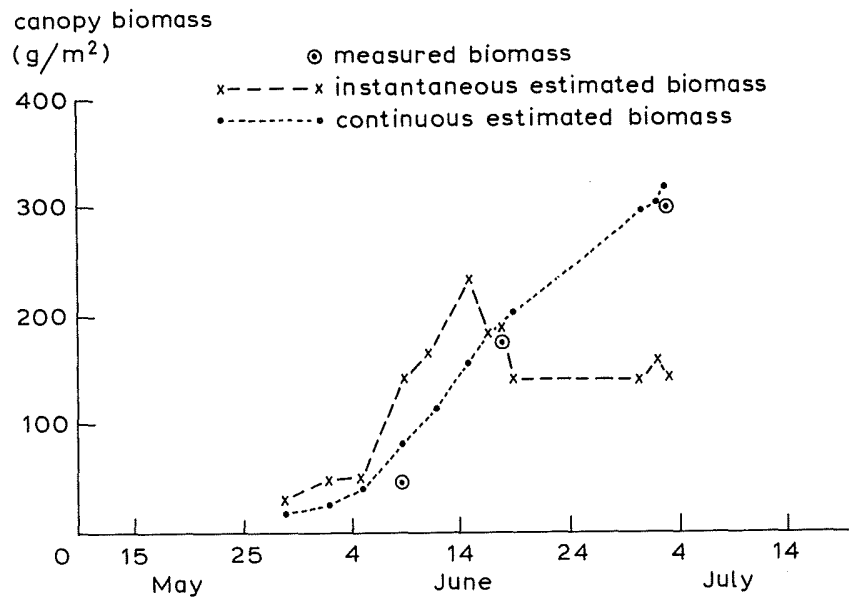

(a)

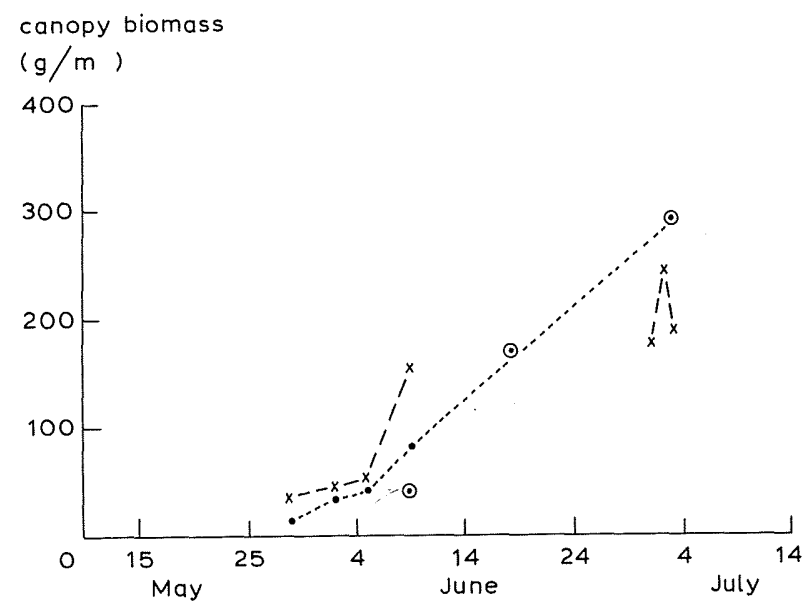

(b)

Figure 5. Measured and estimated dry canopy biomass of beet, 1981. Estimated biomass based on the cloud equations of $(a) 1980$ and $(b) 1979$.

cloud parameters in 1979 only seven radar measurements could be inverted. The values of the backscattering from 10 June to 1 July exceeded the theoretical maximum of the $1979 C$ values (table 1). This suggested that the cloud parameters from 1980 were better. The continuously estimated biomass based on the cloud parameters and the conversion efficiency from 1979, however, was just as efficient as those from 1980.

\section{Discussion}

The method of calculating dry biomass through the accumulation of the estimated rate of crop growth resulted in an improvement over the method of calculating the direct estimation of biomass. For potential use in the prediction of biomass from 
radar remote sensing, information should be available on the amount of daily incoming radiation for the site under consideration. This information is routinely gathered at most meteorological stations and can be input, along with other relevant information such as topographic data and a crop type inventories, into any geographical information system. The radar system should deploy at least two, but preferably more, grazing angles from medium to high elevation angles. Based on the measurements used for this study, the backscattering measurements have to be calibrated with an absolute accuracy of $1 \mathrm{~dB}$ or less.

The prospects for the application of the method we have developed depends on the accuracy with which the cloud parameters and the conversion efficiencies can be determined. They also depend on the amount by which these parameters and efficiencies vary between different crop varieties and regional and climatological conditions.

Table 1 shows the variation that can exist in the cloud parameters for the same crop. The parameters for the crops in 1980 were derived from experiments at a location different from the one in 1979. In a previous study Bouman (1987) showed that the differences in cloud parameters for beet do not relate to differences in crop biomass or soil cover. The effects of the canopy structure and the plant water density on the cloud parameters is still, mostly, an unknown factor. Even if the cloud parameters are chosen correctly, the inversion of backscattering data to an estimation of the microwave soil cover still remains troublesome due to the variability in the radar measurements (figure $1(b)$. Since much of this variation is caused by seasonal

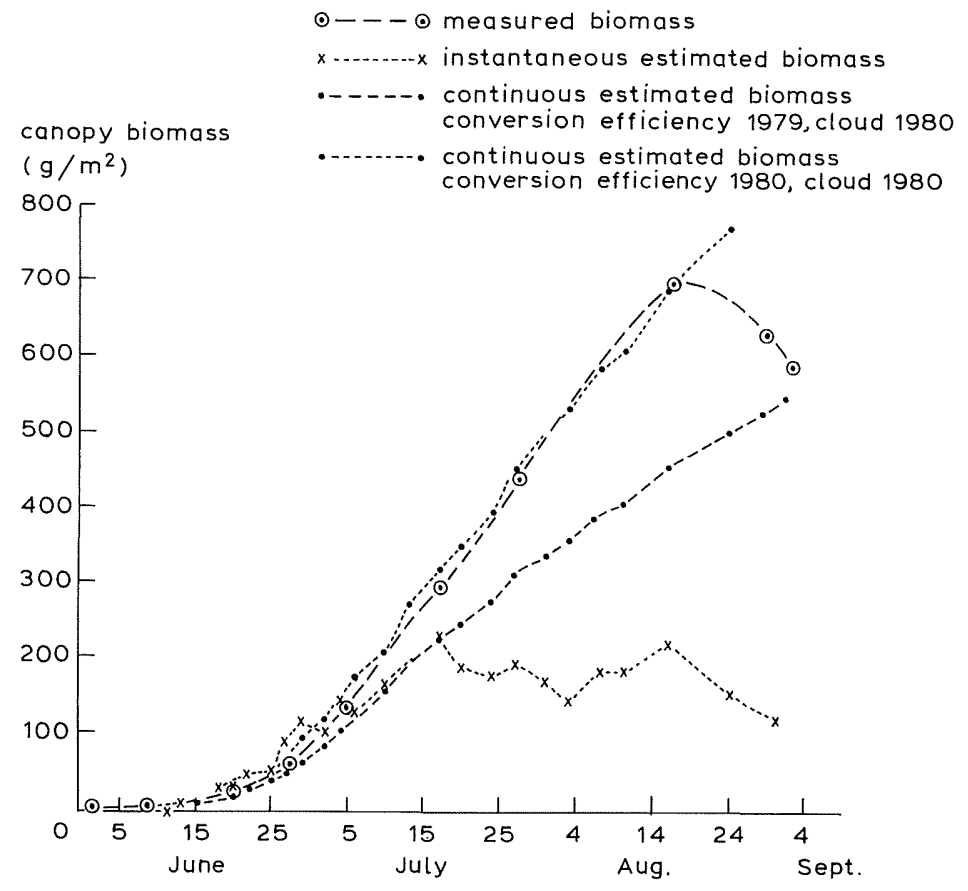

Figure 6. Measured and calculated dry canopy biomass of beet, 1979. The estimated biomass was found from the microwave soil cover through inversion of the backscattering data using the cloud parameters of 1980, and from the coefficient of regression $\beta$ and the conversion efficiency $\alpha$ derived from the experiments in both 1979 and 1980 . 
influences on the structure of the crop canopy, some improvement might be obtained by averaging the backscattering measurements over a number of sequential days.

The variation that occurs in the conversion efficiencies is demonstrated in table 2. It is only for potatoes that this factor is the same for both years. In theory, the linear relationship between the crop's growth rate and the intercepted global radiation is stable over a fairly wide range of external conditions. However, at various sites, deviations in the relationship for the same crop have been reported. These deviations could be due to errors in measurement, temperature differences, drought stress and diseases. Haverkort and Harris (1986) reported a range of conversion efficiencies for potato crops at a single location and related the variation to differences in air temperature. For potential use in the prediction of biomass, the method we developed should be extended to include the influences of external conditions and the limits of its applicability should be studied.

Despite the variations that occur in the cloud parameters and the conversion efficiencies for 1979 and 1980, a remarkable consistency was observed for beet when they were combined in the method we developed (figure 5). The lower value for the coefficient of attenuation, $D$, found in 1980, needed for the calculation of the microwave soil cover, was matched by a higher value for the conversion efficiency, $\alpha$. When the biomass of beet in 1979 was calculated with the cloud parameters from 1980 and the conversion efficiency from 1979, the canopy biomass was seriously underestimated. When the canopy biomass in 1979 was predicted with all parameters from 1980 , the biomass was estimated with the same accuracy as with the fitted parameters in 1979 themselves (figure 6). No explanation for this consistency in results has been found so far.

\section{Acknowledgments}

The authors would like to thank the Netherlands Remote Sensing Board (BCRS) for their financial support of this work.

\section{References}

Attema, E. P. W., and Ulaby, F. T., 1978, Vegetation modeled as a water cloud. Radio Science, 13, 357-364.

Binnenkade, P., 1986, The determination of optimum parameters for identification of agricultural crops with airborne SLAR data. Proceedings of the 7th International Symposium of the ISPRS Commission VII: Interpretation of Photographic and Remote Sensing Data, held in Enschede, The Netherlands, on 25-29 August 1986 (Rotterdam: Balkema Publishers), pp. 111-115.

Bouman, B. A. M., 1987, The radar backscatter from three agricultural crops: beets, peas and potatoes. Centre for Agrobiological Research report 71, Wageningen, The Netherlands.

Bouman, B. A. M., 1988, The microwave backscatter from beets, peas and potatoes throughout the growing season. Proceedings of the 4th International Colloquium on Spectral Signatures of Objects in Remote Sensing held in Aussois (Modave), France on 18-22 January 1988, ESA SP-287 (Paris: European Space Agency), pp. 25-30.

ESA Land Applications Working Group, 1987, Remote Sensing for Advanced Land Applications, ESA SP-1075, Revision 1 (Paris: European Space Agency).

Gallagher, J. N., and Biscoe, P. V., 1978, Radiation absorption, growth and yield of cereals. Journal of Agricultural Science, 91, 47-60.

HAVERKort, A. J., and HARRIS, P. M., 1986, Conversion coefficients between intercepted solar radiation and tuber yields of potato crops under tropical highland conditions. Potato Research, 29, 529-533.

HoEkman, D. H., 1981, Modelvorming radar backscatter voor gewassen (in Dutch). Masters Thesis, Report 05-1-533-AV-90'81, Delft University of Technology, Department of Electrical Engineering, The Netherlands. 
Hoogeboom, P., 1983, Classification of Agricultural Crops in Radar Images. I.E.E.E. Transactions on Geoscience and Remote Sensing, 21, 329-336.

Hoogeboom, P., 1986, Identifying agricultural crops in radar images. Proceedings of the 7 th International Symposium of the ISPRS Commission VII: Interpretation of photographic and Remote Sensing Data, held in Enschede, The Netherlands, 25-29 August 1986 (Rotterdam: Balkema Publishers), pp. 131-137.

KASTEREN, H. W. VAN, 1981, Radar signature of crops. The effect of weather conditions and the possibilities of crop discrimination with radar. Proceedings of Signatures spectrales d'objets en télédétection held in Avignon on 8-11 September 1981. (Paris: European Space Agency), pp. 407-415.

LooR, G. P. DE, 1985, Moisture determination in and under vegetation canopies. Report, Physics and Electronics Laboratory TNO (Toegepast Natuurkundig Onderzoek), No. FEL 1985-52, The Hague, The Netherlands.

Loor, G. P. De, Hoogeboom, P., and Attema, E. P. W., 1982, The Dutch ROVE program. I.E.E.E. Transactions on Geoscience and Remote Sensing, 20, 3-11.

Milthorpe, F. L., and Moorby, J., 1979, An Introduction to Crop Physiology (Cambridge: Cambridge University Press).

Monteith, J. L., 1981, Does light limit production? In Physiological Processes Limiting Plant Productivity, edited by C. B. Johnson (London: Butterworths).

Ulaby, F. T., and Allen, C. T., 1984, Modelling the polarization dependence of the attenuation in vegetation canopies. Proceedings of IGARSS '89 Symposium held in Strasbourg on 27-30 August 1984. (New York: I.E.E.E.), pp. 119-124. 